\title{
La Conferencia sobre el Futuro de Europa
}

\section{Juan González Mellizo}

Representación en España de la Comisión Europea

Juan.GONZALEZ-MELLIZO@ec.europa.eu

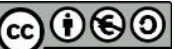

Recepción: enero 2022

Aceptación: enero 2022

Publicación: enero 2022

Cita recomendada: GONZÁLEZ MELLIZO, J. (2022). "La Conferencia sobre el Futuro de Europa". Quaderns IEE: Revista de l'Institut d'Estudis Europeus, 1 (1), 191-198. - DOI « https://doi.org/10.5565/rev/quadernsiee.16 »

\section{Resumen}

La Conferencia sobre el Futuro de Europa es un foro de debate y reflexión, lanzado en mayo de 2021, donde la ciudadanía europea y la sociedad civil organizada están aportado ideas y opiniones sobre el porvenir institucional de la Unión Europea (UE). Se trata de una iniciativa conjunta del Parlamento Europeo, el Consejo de la UE y la Comisión Europea, que se han comprometido a dar seguimiento -en sus respectivos ámbitos de competencia- a las recomendaciones formuladas durante el proceso.

En este artículo se presenta el funcionamiento de la Conferencia, poniendo especial énfasis en los Paneles Ciudadanos.

Palabras clave: Ciudadanía europea; Futuro de la Unión Europea; Participación ciudadana; Sociedad civil; Reformas institucionales.

Abstract. The Conference on the Future of Europe

The Conference on the Future of Europe is a forum for debate and reflection, launched in May 2021, where European citizens and organized civil society are contributing ideas and opinions on the institutional future of the European Union (EU). It is a joint initiative of the European Parliament, the Council of the EU and the European Commission, which have undertaken to follow up -in their respective spheres of competence- on the recommendations made during the process.

This article presents the functioning of the Conference, placing special emphasis on the Citizen Panels.

Keywords: European citizenship; Future of the European Union; Citizen participation; Civil society; Institutional reforms. 
Resum. La Conferència sobre el Futur d'Europa

La Conferència sobre el Futur d'Europa és un fòrum de debat i reflexió, llançat el maig del 2021, on la ciutadania europea i la societat civil organitzada estan aportant idees i opinions sobre el futur institucional de la Unió Europea (UE). Es tracta d'una iniciativa conjunta del Parlament Europeu, el Consell de la UE i la Comissió Europea, que s'han compromès a fer seguiment - en els seus àmbits de competència respectius- a les recomanacions formulades durant el procés.

En aquest article es presenta el funcionament de la Conferència, posant especial èmfasi als Panells Ciutadans.

Paraules clau: Ciutadania europea; Futur de la Unió Europea; Participació ciutadana; Societat civil; Reformes institucionals. 


\author{
Sumario \\ 1. Una consulta democrática, paneuropea, única y sin precedentes \\ 2. La gobernanza de la COFE: una metodología innovadora \\ 3. Paneles de ciudadanos europeos \\ 4. Actividad en la plataforma digital \\ 5. Próximos pasos \\ Referencias
}

\title{
1. UNA CONSULTA DEMOCRÁTICA, PANEUROPEA, ÚNICA Y SIN PRECEDENTES
}

La Comisión Europea, el Parlamento Europeo y el Consejo de la Unión Europea lanzaron, al inicio de su actual mandato, un ejercicio de consulta democrática paneuropea única y sin precedentes en la historia de la Unión Europea (UE, en adelante): la Conferencia sobre el Futuro de Europa (COFE, en adelante ${ }^{1}$ ).

Se trata de una oportunidad única para que los ciudadanos expongan sus propuestas en torno a Europa y puedan debatir abiertamente sobre los retos y las prioridades que deben marcarse las instituciones europeas para el futuro.

La COFE nació con la vocación de acercar la UE a sus ciudadanos y, sobre todo, conocer de primera mano sus expectativas y deseos sobre el funcionamiento de las instituciones europeas en las áreas y políticas que más les afectan. Lo que nadie se podía imaginar cuando se puso en marcha el proyecto era la cruel sacudida que esperaba al mundo en forma de pandemia. Una sacudida que ha cambiado el orden geopolítico mundial y el papel de la UE, tanto fuera de nuestras fronteras como en el seno de sus propias políticas.

Este proceso de consulta democrática ha arrancado, pues, en un contexto que difiere radicalmente del punto de partida inicial. Pero no por ello ha perdido relevancia, más bien todo lo contrario. Pasan ahora a un primer plano cuestiones como las competencias que la UE debe tener en materia de salud, su autonomía estratégica en áreas como las nuevas tecnologías, la lucha contra el cambio climático (piedras angulares para la obtención de los fondos europeos para la recuperación económica) o la necesidad de una Europa más social, entre otras.

\footnotetext{
${ }^{1}$ También se utilizan las siglas CoFoE, pero en este texto se opta por COFE.
} 


\section{LA GOBERNANZA DE LA COFE: UNA METODOLOGÍA INNOVADORA}

La gobernanza de un proyecto de la magnitud de una consulta ciudadana simultánea en 27 países implica, además de a los ciudadanos — cuya activa participación es el eje central de todo el ejercicio-, a todos los actores políticos a nivel nacional y europeo, y a la sociedad civil. Detrás de un proyecto de esta complejidad y características hay una innovadora metodología que incluye la organización de paneles temáticos con ciudadanos y plenarios institucionales donde la ciudadanía, la sociedad civil y los actores políticos nacionales y europeos debaten conjuntamente —algo inusual en prácticamente cualquier sistema democrático a nivel mundial.

Para que los ciudadanos que no forman parte directamente de este sistema de paneles y plenarios puedan contribuir y participar desde cualquier rincón de Europa, se ha creado una plataforma digital ${ }^{2}$, disponible en todas las lenguas oficiales de la UE. Es un espacio donde cada europeo puede compartir sus ideas sobre temas clave, como, por ejemplo, el medio ambiente, la sanidad, la economía y la educación, entre otros. En la misma plataforma se publica también información sobre actividades (presenciales, virtuales o híbridas) organizadas a nivel nacional y local, con el objetivo de fomentar y estimular el intercambio de ideas. De las discusiones que tienen lugar en la plataforma, se extraen las propuestas más populares y las que generan mayor interés entre los participantes.

Estas ideas se integran y debaten después en los cuatro paneles de ciudadanos que se reúnen de forma presencial y virtual. Cuenta, cada uno, con la participación de alrededor de 200 ciudadanos elegidos de forma aleatoria en los 27 países de la UE. Los paneles también reflejan la diversidad de la UE: por origen geográfico, género, edad, origen socioeconómico y nivel de educación. En cada uno de ellos hay, por lo menos, una ciudadana y un ciudadano por país, y un tercio de los participantes son jóvenes.

Los temas de debate para cada uno de los paneles se basan en los temas de la plataforma digital multilingüe y se agrupan de la manera siguiente:

- Una economía más fuerte, justicia social y empleo; educación, cultura, juventud y deporte; transformación digital.

- Democracia europea; valores y derechos, Estado de Derecho y seguridad.

- Cambio climático y medio ambiente; salud.

- La UE en el mundo; migración.

El objetivo final de los paneles de ciudadanos es formular una serie de recomendaciones que serán objeto de seguimiento por parte de la UE y que se someterán a la valoración del Pleno de la Conferencia, en el que participarán los representantes de los paneles. El Pleno estará igualmente compuesto por representantes del Parlamento Europeo, del Consejo de la UE y de la Comisión Europea, así como por representantes de todos los Parlamentos nacionales, en pie de igualdad,

\footnotetext{
${ }^{2}$ Web del proyecto: https://futureu.europa.eu/
} 
y de sus ciudadanos. También estarán representados el Comité Europeo de las Regiones, el Comité Económico y Social Europeo y organizaciones sociales.

Las ideas que se expresen durante los eventos de la Conferencia y, sobre todo, durante los plenos, se traducirán en recomendaciones concretas para la futura actuación de la UE. Las instituciones de la Unión ya se han comprometido a dar seguimiento concreto a todas estas recomendaciones, dentro de su ámbito de competencia y de conformidad con los Tratados de la UE.

\section{PANELES DE CIUDADANOS EUROPEOS}

Para ilustrar cómo funcionan los paneles ciudadanos, sirva como ejemplo el que se celebró, entre los días 10 y 12 de diciembre de 2021, sobre democracia europea, valores y derechos, Estado de derecho y seguridad, en lo que fue su tercera y última sesión. En la sesión, que tuvo lugar en el Instituto Universitario Europeo (IUE) de Florencia ${ }^{3}$, ciudadanos de diferentes edades y procedencias, de todos los Estados miembros, adoptaron 39 recomendaciones para el futuro de Europa 4 .

Para garantizar que todos los participantes pudieran intervenir, también fue posible la conexión a distancia. Los panelistas se basaron en el trabajo previo de dos sesiones, celebradas en Estrasburgo del 24 al 26 de septiembre y en línea del 12 al 14 de noviembre, y se centraron en los siguientes temas: (i) garantizar los derechos y la no discriminación; (ii) proteger la democracia y el Estado de Derecho; (iii) reformar la UE; (iv) construir la identidad europea; y (v) reforzar la participación ciudadana.

Es de gran interés la lectura completa del informe con las recomendaciones (21 páginas). Para su aproximación se presenta un breve resumen con las ideas principales:

- Que la Unión establezca una serie de criterios en materia de lucha contra la discriminación en el mercado laboral (cuotas para jóvenes, personas mayores, mujeres y minorías).

- Que la Unión prevea un programa de incentivos que facilite la creación de guarderías y parques infantiles a precios asequibles en las grandes y pequeñas empresas.

- Que la Unión haga inversiones públicas que conduzcan a la creación de puestos de trabajo adecuados y a la mejora y armonización de la calidad de vida en toda la Unión.

- Gravar a las grandes empresas para contribuir a las inversiones públicas y centrarse en la eliminación de los paraísos fiscales en la Unión.

\footnotetext{
${ }^{3}$ Sitio web del Instituto Universitario Europeo dedicado a la COFE: https://www.eui.eu/p?id=theconference-on-the-future-of-europe

4 Toda la información relevante se puede consultar en la página dedicada al Panel 2: https://futureu.europa.eu/assemblies/citizens-panels/f/299/
} 
- Salvaguardar el bienestar de los animales y la sostenibilidad de la ganadería mediante la modificación de la Directiva 98/58/CE relativa a la protección de los animales en las explotaciones ganaderas.

- Dejar de subvencionar la agricultura a gran escala, si no conduce a una transición hacia una agricultura ecológica y sostenible.

- Fomentar una agricultura más respetuosa con el medio ambiente y el clima en Europa y en todo el mundo, gravando todas las emisiones negativas, los plaguicidas y el uso extremo del agua, etc., sobre la base de su impacto medioambiental.

- Favorecer una cobertura mediática más independiente, objetiva y equilibrada.

- Invertir en la lucha contra la desinformación.

- Reforzar las competencias de la Unión en materia de protección de datos.

- Actuar con mayor firmeza frente a las nuevas amenazas derivadas de infracciones en materia de ciberseguridad y el uso de la inteligencia artificial con fines delictivos.

- Mejorar la educación sobre la democracia en la Unión y elaborar programas escolares sobre lo que está haciendo la Unión con respecto a los mecanismos de participación existentes.

- Modificar el reglamento relativo a la condicionalidad para que todos los casos de vulneración del Estado de Derecho.

- Cambiar los nombres de las instituciones para aclarar sus funciones.

- Adoptar una ley electoral para el Parlamento Europeo que armonice las normas electorales.

- Celebrar referéndums a escala de la Unión, cuya iniciativa debería corresponder al Parlamento Europeo.

- Que las tecnologías de traducción existentes y emergentes se sigan desarrollando, mejorando y haciendo más accesibles, con el fin de reducir las barreras lingüísticas y fortalecer la identidad común y la democracia en la Unión.

- Facilitar el acceso a la información, con el fin de mejorar la transparencia, la deliberación pública y la democracia.

- Favorecer la interacción -en línea y fuera de línea- entre ciudadanos de la Unión y también con sus representantes.

- Que haya ciudadanos observadores independientes durante todos los procesos de toma de decisiones de la Unión.

- Que se reabra el debate sobre la Constitución Europea.

Por otra parte, el panel de ciudadanos sobre cambio climático, medioambiente y salud se reunió por tercera y última vez del 7 al 9 de enero de 2022. El Colegio de Europa en Natolin (Varsovia, Polonia) acogió el trabajo del panel. Alrededor de 200 ciudadanos europeos de diferentes edades y orígenes se reunieron (en persona y de forma remota) 
y adoptaron 51 recomendaciones sobre los desafíos a los que Europa se tendrá que enfrentar en estas áreas 5

\section{ACTIVIDAD EN LA PLATAFORMA DIGITAL}

Según el tercer informe intermedio de la plataforma ${ }^{6}$, que cubre la actividad desde la puesta en marcha de esta plataforma hasta el 3 de noviembre de 2021, se han registrado 29.012 contribuciones, con 9.337 ideas, 16.017 comentarios y 3.658 eventos que abarcan los diez temas.

Hasta la fecha, los temas «Democracia europea» $\mathrm{y}$ «Cambio climático y medio ambiente» han atraído con diferencia el mayor volumen de contribuciones, seguidos del tema abierto «Otras ideas».

Todos los países de la UE han generado actividad. En total, Alemania registra la cifra más elevada de contribuciones, desde la puesta en marcha de la plataforma; sin embargo, en proporción a su población, los países más pequeños son los que más contribuciones realizan y, entre ellos, Malta destaca como el más activo.

\section{PRÓXIMOS PASOS}

Las recomendaciones de los Paneles Ciudadanos Europeos se presentarán y debatirán en el Pleno de la Conferencia, donde se seguirán perfilando las propuestas de la misma. Ochenta representantes de los Paneles (20 de cada uno de los Paneles Ciudadanos Europeos, de los cuales al menos un tercio tiene entre 16 y 25 años) son miembros del Pleno de la Conferencia. Allí presentarán los resultados de los debates de sus respectivos paneles y los debatirán con los diputados del Parlamento Europeo, los representantes de los gobiernos y parlamentos nacionales, los comisarios europeos y otros miembros del Pleno procedentes de organismos de la UE, autoridades regionales y locales, interlocutores sociales y la sociedad civil.

La próxima Conferencia Plenaria está prevista para finales de enero del 2022 en Estrasburgo. Los ciudadanos de toda Europa pueden seguir participando en la Conferencia a través de la Plataforma Digital Multilingüe.

Para concluir, la voluntad de la UE y el objetivo de la Conferencia sobre el Futuro de Europa es involucrar a los ciudadanos en mayor medida en la construcción del proyecto europeo y desarrollar el concepto de democracia participativa en su más amplio sentido. Según el Eurobarómetro sobre el Futuro de Europa ${ }^{7}$ publicado en marzo de 2021, el $70 \%$ de los españoles opina que la Conferencia representará un

\footnotetext{
${ }^{5}$ Los informes y recomendaciones del Panel europeo de ciudadanos 3: «Cambio climático y medio ambiente / Salud» se pueden consultar en: https://futureu.europa.eu/assemblies/citizenspanels/f/300/

6 En la página de Informes se pueden consultar los "Informes de actividad" y los "Informes de la plataforma": https://futureu.europa.eu/pages/reporting

${ }^{7}$ Web: https://europa.eu/eurobarometer/surveys/detail/2256
} 
progreso en la democracia de la UE, lo que se corresponde con la ambición europea para esta iniciativa.

\section{REFERENCIAS}

COFE (2021). Panel europeo de ciudadanos 2: «Democracia europea / Valores y derechos, Estado de Derecho y seguridad». Recomendaciones.

https://futureu.europa.eu/assemblies/citizens-panels/f/299/

[el enlace incluye todos los informes del Panel 2].

COFE (2021). Plataforma digital multilingüe de la Conferencia sobre el Futuro de Europa Tercer informe provisional. Noviembre de 2021.

https://futureu.europa.eu/pages/reporting

[el enlace incluye todos los informes de la plataforma].

European Parliament \& European Commission (2021). Future of Europe: Special Eurobarometer 500 Report. Fieldwork: October-November 2020.

https://europa.eu/eurobarometer/surveys/detail/2256 